\title{
Apolipoprotein E Prevents the Progression of Atherosclerosis in Watanabe Heritable Hyperlipidemic Rabbits
}

\author{
Nobuhiro Yamada, Ikuo Inoue, Masako Kawamura, Kenji Harada, Yoshiro Watanabe, Hitoshi Shimano, Takanari Gotoda, \\ Masako Shimada, Kohichi Kohzaki, Toyohiro Tsukada, ${ }^{*}$ Masashi Shiomi, ${ }^{\star}$ Yoshio Watanabe, ${ }^{\star}$ and Yoshio Yazaki \\ 3rd Department of Internal Medicine, University of Tokyo, Hongo, Tokyo, Japan; *Sanraku Hospital, Tokyo, Japan; \\ and ${ }^{\ddagger}$ Institute for Experimental Animals, Kobe University, School of Medicine, Kobe, Japan
}

\begin{abstract}
Apo E plays an important role in plasma lipoprotein metabolism through its high affinity binding to cell surface LDL receptor. In the present study, we studied the effects of apo $E$ on the atherogenic process in Watanabe heritable hyperlipidemic rabbits which are deficient in LDL receptor and an animal model for familial hypercholesterolemia. We isolated apo $E$ from plasma of $1 \%$ cholesterol-fed rabbits and administered $10 \mathrm{mg}$ of purified apo $\mathrm{E}$ intravenously into five Watanabe heritable hyperlipidemic rabbits three times a week from their age of 2.5 months to 11 months for 8.5 months. After sustained administration of apo $\mathbf{E}$, we found a significant reduction in the accumulation of cholesterol ester in aortae $(1.55 \pm 0.07 \mathrm{mg} / \mathrm{g}$ tissue) as compared to control rabbits $(4.32 \pm 0.61 \mathrm{mg} / \mathrm{g}$ tissue). Supporting this, the percentage of the surface area of the aorta with macroscopic plaque was remarkably decreased in apo Etreated animals (18.8 $\pm 5.1 \%$ vs. $38.8 \pm 8.0 \%$ in control). Thus, apo $\mathrm{E}$ definitely prevented the progression of atherosclerosis in Watanabe heritable hyperlipidemic rabbits. (J. Clin. Invest. 1992.89:706-711.) Key words: apolipoprotein E•atherosclerosis - Watanabe heritable hyperlipidemic rabbit - low density lipoprotein receptor $\bullet$ cholesterol
\end{abstract}

\section{Introduction}

Apo E functions in plasma lipoprotein metabolism through its interaction with cell surface receptors such as LDL receptor (1-5) and apo E receptor (LDL receptor-related protein) $(6,7)$. Recently, we and others demonstrated a reduction in plasma cholesterol levels after intravenous administration of apo $\mathrm{E}$ into Watanabe heritable hyperlipidemic (WHHL) ${ }^{1}$ rabbits (8, 9). Exogenous apo E was incorporated into plasma lipoproteins

Address correspondence to Nobuhiro Yamada, M. D., 3rd Department of Internal Medicine, University of Tokyo, Hongo, Tokyo, Japan.

Received for publication 6 August 1991 and in revised form 22 October 1991.

1. Abbreviation used in this paper: WHHL, Watanabe heritable hyperlipidemic.

J. Clin. Invest.

(C) The American Society for Clinical Investigation, Inc.

0021-9738/92/02/0706/06 \$2.00

Volume 89, February 1992, 706-711 including VLDL, then VLDL enriched in apo $\mathrm{E}$ was removed rapidly from the blood through mutant LDL receptor or apo $E$ receptor in WHHL rabbits, and induced the reduction in plasma cholesterol levels. This function of apo $\mathrm{E}$ is supposed to reduce the rate of atherogenesis because many studies have proved the relationship between plasma cholesterol level and the incidence of coronary heart disease $(10,11)$.

Many studies have suggested important roles of apo $E$ in lipid transport in various tissues, including liver, brain, peripheral nerves, and arterial walls, as well as in plasma (3, 12-14). However, in vivo effects of apo $\mathrm{E}$ are not fully understood; in particular, its effects on atherogenesis are controversial. Apo E secreted from macrophages is proposed to function in cholesterol efflux from cholesterol-loaded cells collaborating with HDLs in the interstitial fluid $(15,16)$; this function is considered to be related to the regression of atherosclerosis by reducing intracellular cholesterol of foam cells. In contrast, apo Erich lipoproteins such as $\beta$-VLDL and hypertriglyceridemic VLDL have been considered to be atherogenous from in vitro studies $(17,18)$, because macrophages actively endocytose lipoproteins containing several molecules of apo $\mathrm{E}$, and transform to foam cells in vitro. Our recent study also demonstrated the enhanced uptake of apo E-rich VLDL in human monocytederived macrophages (19). The apo E secreted from macrophages can be incorporated into VLDL, and VLDL enriched in apo $E$ is actively taken up by macrophages with a high affinity to cell surface receptors. Both functions of apo $E$ that are related to cholesterol efflux from macrophages and cholesterol uptake by macrophages, may play an important role in pathophysiology of atherosclerosis. To understand an overall effect of apo $E$ on the process of atherosclerosis in vivo, we administered rabbit apo $\mathrm{E}$ into WHHL rabbits, an animal model of early atherosclerosis, for 8.5 months in the present study.

\section{Methods}

Animal experiments. 10 male WHHL rabbits from six litters, weighing $\sim 1.5 \mathrm{~kg}$, were fed laboratory chow ad lib. and housed individually before and during the experiments.

Apo E. Apo E was purified from plasma of rabbits fed a diet containing $1 \%$ cholesterol by weight for $>1 \mathrm{mo}$. Plasma from blood containing $0.1 \%$ EDTA and $0.02 \%$ sodium azide was ultracentrifuged at $d$ $=1.03 \mathrm{~g} / \mathrm{ml}$ for $20 \mathrm{~h}$ at $16^{\circ} \mathrm{C}$ in a 50.2 rotor of an ultracentrifuge at 45,000 rpm (Beckman Instruments, Inc., Palo Alto, CA); the supernatant lipoproteins were recentrifuged under the same condition to obtain lipoproteins rich in apo $E(8)$. All steps of purification were carried out at $4^{\circ} \mathrm{C}$. After delipidation of the lipoproteins by extraction with 200 
vol of ethanol-ether (1:1) four times and evaporating the solvent under $\mathrm{N}_{2}$, apolipoproteins were dissolved in $2 \mathrm{mM}$ sodium phosphate, $\mathrm{pH} 7.4$ containing $6 \mathrm{M}$ urea, dialyzed against $2 \mathrm{mM}$ sodium phosphate containing $50 \mathrm{mM} \mathrm{NaCl}$ and $1 \mathrm{M}$ urea, $\mathrm{pH} 7.4$ (buffer A), and applied to a column $(2 \times 16 \mathrm{~cm})$ of heparin-Sepharose 4B (Pharmacia Fine Chemicals, Uppsala, Sweden) preequilibrated with $2 \mathrm{mM}$ sodium phosphate containing $50 \mathrm{mM} \mathrm{NaCl}$, pH 7.4 (buffer B). The column was first washed with $100 \mathrm{ml}$ of buffer $A$, then with $1,200 \mathrm{ml}$ of buffer $B$, and finally with $2 \mathrm{mM}$ sodium phosphate containing $500 \mathrm{mM} \mathrm{NaCl}$ and 6 $\mathrm{M}$ urea, $\mathrm{pH} 7.4$, to elute apo $\mathrm{E}$. The purity of apo $\mathrm{E}$ was evaluated by SDS polyacrylamide gel electrophoresis (8) and purity was $>99 \%$. After dialysis against water and lyophilization, purified apo $\mathrm{E}$ was stored at $-80^{\circ} \mathrm{C}$. One day before use, apo $\mathrm{E}$ was dissolved in $6 \mathrm{M}$ guanidine chloride, $\mathrm{pH} 7.4$, at a concentration of $\sim 20 \mathrm{mg} / \mathrm{ml}$, and finally dialyzed extensively against $150 \mathrm{mM} \mathrm{NaCl}$. We prepared $\sim 5 \mathrm{~g}$ of apo $\mathrm{E}$ for the current study, which was pooled and used as a single lot.

In vivo studies. The experiment was started at the age of $2.5 \mathrm{mo}$ in WHHL rabbits. $10 \mathrm{mg}$ of sterile rabbit apo $\mathrm{E}$ in $0.5 \mathrm{ml}$ of $0.15 \mathrm{M} \mathrm{NaCl}$ was administered intravenously by a bolus injection through a marginal ear vein every Monday, Wednesday, and Friday morning for 8.5 mo. In control rabbits, $0.5 \mathrm{ml}$ of $0.15 \mathrm{M} \mathrm{NaCl}$ was injected to evaluate the natural course of atherosclerosis. Each animal group consisted of five rabbits from five litters. Before starting the experiment, and 2 and 6 mo after starting the experiment, $2 \mathrm{ml}$ of blood was taken to measure plasma cholesterol (20), triglyceride levels by enzymatic methods (21), and HDL-cholesterol level by precipitation method (22), one day after apo $\mathrm{E}$ injection. After $8.5 \mathrm{mo}$ of the experiment, $5 \mathrm{ml}$ of blood was drawn to evaluate blood cell counts, liver functions, kidney functions, and plasma lipid levels.

Extent of atherosclerotic lesions. Animals were killed under deep anesthesia with xylazine at $7 \mathrm{mg} / \mathrm{kg}$ and ketamine at $80 \mathrm{mg} / \mathrm{kg}$ intramuscularly. The entire aorta from the aortic valve to the iliac bifurcation was removed and cleaned of loose adventitial tissue. For the analysis, the aorta was divided into three segments at the levels of the first intercostal artery and celiac artery (aortic arch, descending thoracic aorta, and abdominal aorta). We measured contents of cholesteryl ester in each segment of aorta to confirm macroscopic observations. Each segment of aorta was dried by lyophilization and stored at $-20^{\circ} \mathrm{C}$ until analysis. Total lipid extracts were prepared by cutting each aorta into small pieces and homogenizing three times in chloroform/methanol (2:1) in a tapered glass-glass homogenizer. Determinations of total and free cholesterol in the extracts were performed in triplicate by enzymatic assay.

Furthermore, we determined the extent of lesion area with macroscopic atherosclerotic plaques. The aorta was opened longitudinally, covered with a clear plastic sheet, and copied with a magnification of 2 , then the areas corresponding to atheromatous plaques on the copied paper were delineated. The delineated areas of atheromatous lesions were scanned and estimated by computer. The lesion areas within each segment were summed and the extent of lesions was expressed as percentage of surface area with atheromatous plaque.

Statistical analysis. All data were expressed as mean \pm SD. We compared data between groups by analysis of variance, and the statistical difference was determined by Student's $t$ tests.

\section{Results}

Plasma lipid levels. Plasma cholesterol levels and triglyceride levels were over $400 \mathrm{mg} / \mathrm{dl}$ and $300 \mathrm{mg} / \mathrm{dl}$, respectively, and plasma HDL-cholesterol levels were $6-9 \mathrm{mg} / \mathrm{dl}$ as shown in Table I. There were no significant differences between the two groups, but we found decrease in plasma cholesterol levels in both animal groups after the experiment as compared to before the experiment. Mean plasma apo E level increased 54\% 3 min
Table I. Changes in Plasma Cholesterol, Triglyceride, and HDLCholesterol Levels $(\mathrm{mg} / \mathrm{dl})$ after the Administration of Rabbit apo $E(n=5)$ and Saline $(n=5)$ in Male WHHL Rabbits

\begin{tabular}{lcccc} 
& \multicolumn{5}{c}{ Months after starting experiments } \\
\cline { 2 - 5 } Group & 0 & 2 & 6 & 8.5 \\
\hline Cholesterol $(m g / d l)$ & & & & \\
$\quad$ Apo E & $502 \pm 33$ & $490 \pm 39$ & $431 \pm 83$ & $408 \pm 42$ \\
$\quad$ Control & $518 \pm 15$ & $512 \pm 19$ & $440 \pm 65$ & $418 \pm 46$ \\
Triglyceride $(m g / d l)$ & & & & \\
$\quad$ Apo E & $415 \pm 91$ & $422 \pm 116$ & $325 \pm 67$ & $328 \pm 59$ \\
Control & $365 \pm 82$ & $368 \pm 122$ & $387 \pm 93$ & $378 \pm 181$ \\
HDL-cholesterol & & & & \\
$\quad(m g / d l)$ & & & & \\
Apo E & $7.0 \pm 2.2$ & $6.0 \pm 1.7$ & $6.0 \pm 0.86$ & $6.0 \pm 1.5$ \\
Control & $8.2 \pm 1.6$ & $6.8 \pm 2.0$ & $6.7 \pm 1.9$ & $7.9 \pm 1.0$ \\
& & & &
\end{tabular}

Serum lipid levels were measured by enzymatic assay. Male WHHL rabbits weighing $\sim 1.5 \mathrm{~kg}$ were fed laboratory chow ad lib. Apo E was purified from plasma of rabbits fed a diet containing $1 \%$ cholesterol by weight for more than 1 month (6). We prepared $\sim 5 \mathrm{~g}$ of apo E for the current study, which was pooled and used as a single lot. The experiment was started at the age of 2.5 months in WHHL rabbits. We checked the daily intake of diet every day; there were no significant differences in the mean food consumption. Body weight gains during the experiment were not significantly different between the two groups. We did not find any differences in peripheral blood cell counts, liver functions or kidney functions between the groups after 8.5 months of treatment.

Values are expressed as mean $\pm \mathrm{SD}$.

after apo $\mathrm{E}$ injection as compared to preinjection level, and the half-life of injected apo $\mathrm{E}$ was $1.5 \mathrm{~h}$ in a different set of studies using WHHL rabbits $(n=3)$. We checked daily intake of diet every day; there were no significant differences in the mean food consumption. Body weight gains during the experiment were not significantly different between the two groups (1.5 \pm 0.1 to $3.2 \pm 0.2 \mathrm{~kg}$ : apo $\mathrm{E} 1.5 \pm 0.1$ to $3.2 \pm 0.2 \mathrm{~kg}$ : saline). We did not find any differences in peripheral blood cell counts, liver functions, and kidney functions between the two groups after 8.5 months treatment.

Extent of aortic atherosclerosis. There was a remarkable reduction in the accumulation of cholesterol ester in aortae from animals treated with apo $\mathrm{E}$ as compared with those treated with saline (apo E: $1.55 \mathrm{mg} / \mathrm{g}$ aorta, saline: $4.32 \mathrm{mg} / \mathrm{g}$ aorta, Table II). The accumulation of cholesterol ester in each segment of aorta was significantly less in animals treated with apo $\mathrm{E}$ than those with saline $(P<0.001$, Table II). Supporting these observations, the lesion area with atherosclerotic plaque in the apo E group was much smaller than that in the saline group ( $18.8 \%$ vs. $38.8 \%, P<0.002$, Table III and Fig. 1). In particular, the extent of the lesion area in the aortic arch was very different between these two groups $(P<0.001)$. Percentages of lesion areas of descending thoracic aorta and abdominal aorta in animals treated with apo $\mathrm{E}$ were significantly different from those with saline $(P<0.02$ and $P<0.02$, respectively). Visual examinations showed the thickness of atherosclerotic plaques to be apparently minimal in animals treated with apo E (Fig. 1). In the immunocytochemical study with antibody 
Table II. Contents of Cholesterol Ester of Each Aortic Arch, Descending Thoracic Aorta, Abdominal Aorta, and Total Aorta in WHHL Rabbits Treated with Rabbit apo E or Saline

\begin{tabular}{lccccc}
\hline & \multicolumn{5}{c}{ Cholesterol ester (mg) } \\
\cline { 2 - 6 } Group & Aortic arch & Thoracic & Abdominal & Total aorta & Cholesterol ester/dry tissue \\
\hline Apo E-1 & 0.20 & 0.10 & 0.08 & 0.38 & 1.58 \\
Apo E-2 & 0.21 & 0.11 & 0.03 & 0.35 & 1.52 \\
Apo E-3 & 0.21 & 0.11 & 0.10 & 0.42 & 1.50 \\
Apo E-4 & 0.19 & 0.08 & 0.02 & 0.31 & 1.48 \\
Apo E-5 & 0.20 & 0.18 & 0.05 & 0.43 & 1.65 \\
Mean \pm SD & $0.20 \pm 0.01^{*}$ & $0.12 \pm 0.04^{*}$ & $0.06 \pm 0.03^{*}$ & $0.38 \pm 0.05^{*}$ & 3.87 \\
Control-1 & 0.56 & 0.21 & 0.12 & 0.89 & 1.14 \\
Control-2 & 0.71 & 0.25 & 0.18 & 1.19 & 1.11 \\
Control-3 & 0.68 & 0.34 & 0.17 & 1.19 & 4.75 \\
Control-4 & 0.61 & 0.35 & 0.15 & 0.16 & 4.76 \\
Control-5 & 0.68 & 0.35 & $0.16 \pm 0.02$ & 0.12 & 4.47 \\
Mean \pm SD & $0.65 \pm 0.06$ & $0.30 \pm 0.07$ & & $4.32 \pm 0.61$
\end{tabular}

${ }^{*} P<0.001$. Cholesterol ester/dry tissue indicates contents of cholesterol ester (in milligrams) per weight of dry total aorta (in grams). The apo $\mathrm{E}$ group was compared to the saline group. Each segment of aorta was dried by lyophilization and stored at $-20^{\circ} \mathrm{C}$ until analysis. Total lipid extracts were prepared by cutting each aorta into small pieces and homogenizing it three times in chloroform/methanol (2:1) in a tapered glassglass homogenizer. Determinations of total and free cholesterol in the extracts were performed in triplicate by enzymatic assay.

specific for smooth muscle cells (HHF 35) and macrophages (RAM 11) (23), we found the similar distribution of both cell types in the atherosclerotic lesions of both groups. As compared to the percentage lesion area, the cholesterol ester con-

Table III. Percentages of Intimal Surface Area with Atheromatous Plaque of Each Aortic Arch, Descending Thoracic Aorta, Abdominal Aorta, and Total Aorta in WHHL Rabbits Treated with Rabbit apo E or Saline

\begin{tabular}{ccccc}
\hline & \multicolumn{4}{c}{ Percent lesion area } \\
\cline { 2 - 5 } Group & Aortic arch & Thoracic & Abdominal & Total aorta \\
\hline Apo E-1 & 30 & 9 & 9 & 14 \\
Apo E-2 & 33 & 11 & 5 & 14 \\
Apo E-3 & 41 & 15 & 9 & 18 \\
Apo E-4 & 34 & 30 & 13 & 25 \\
Apo E-5 & 42 & 24 & 8 & 23 \\
Mean \pm SD & $36.0 \pm 5.2^{*}$ & $17.8 \pm 8.9^{\ddagger}$ & $8.8 \pm 2.9^{\ddagger}$ & $18.8 \pm 5.1^{8}$ \\
Control-1 & 54 & 32 & 10 & 27 \\
Control-2 & 86 & 30 & 18 & 38 \\
Control-3 & 78 & 51 & 26 & 49 \\
Control-4 & 77 & 30 & 16 & 38 \\
Control-5 & 82 & 40 & 23 & 42 \\
Mean $\pm S D$ & $75.4 \pm 12.5$ & $36.6 \pm 9.0$ & $18.6 \pm 6.2$ & $38.8 \pm 8.0$ \\
& & & & \\
\hline
\end{tabular}

${ }^{*} P<0.001 ;{ }^{\ddagger} P<0.02 ;{ }^{8} p<0.002$. The apo $\mathrm{E}$ group was compared to the control group. The entire aorta from the aortic valve to the iliac bifurcation was removed and opened longitudinally. The aorta, covered with a clear plastic sheet, was copied with a magnification of 2 and the area corresponding to atheromatous plaques on the copied paper was delineated. The delineated areas of atheromatous lesions were estimated as lesioned area. The aorta was divided into three segments at the levels of the first intercostal artery and celiac artery (aortic arch, descending thoracic aorta, and abdominal aorta). tents of the aortae were extremely reduced in animals treated with apo $\mathrm{E}$, and those variations among animals were much smaller. When the ratios of cholesterol ester accumulation to lesion area were compared between two groups, we could not find significant differences in the ratios between the two groups as shown in Fig. 2.

\section{Discussion}

In recent studies, we have suggested the possible involvement of apo $\mathrm{E}$ in the process of atherosclerosis $(8,19)$. The present study tried to determine the effects of apo $\mathrm{E}$ on its process in vivo. One of the best ways to evaluate the effects of agents that can affect the rate of atherogenesis in vivo is long-term administration of such agents to young WHHL rabbits that have not yet developed atherosclerotic lesions $(24,25)$. Plasma cholesterol levels in WHHL rabbits are $>400 \mathrm{mg} / \mathrm{dl}$, and severe, progressive atherosclerosis occurs after the age of 4 months (26). In the present study, we injected a relatively low dose of apo $\mathrm{E}(10 \mathrm{mg} /$ animal per day) into young WHHL rabbits ( 2.5 months) as compared to the previous study, in which apo $E$ was shown to significantly reduce plasma cholesterol levels after treatment with $30-40 \mathrm{mg}$ of apo E. Minimal effects on plasma cholesterol level have been demonstrated in WHHL rabbits after intravenous injection of $10 \mathrm{mg}$ of apo E (27). During the experimental period, there were no significant differences in plasma lipid levels between the two groups.

Apo E definitely reduced the rate of atherogenesis after 8.5 months of treatment in WHHL rabbits. The cholesterol accumulation and lesion area were reduced approximately onethird and one-half, respectively, in animals treated with apo E as compared to those with saline. The cholesterol ester content of each aortic segment was well correlated to percentage lesion area $(r=0.884)$. Similar retarded progression of atherosclerosis without significant change in plasma cholesterol level was dem- 


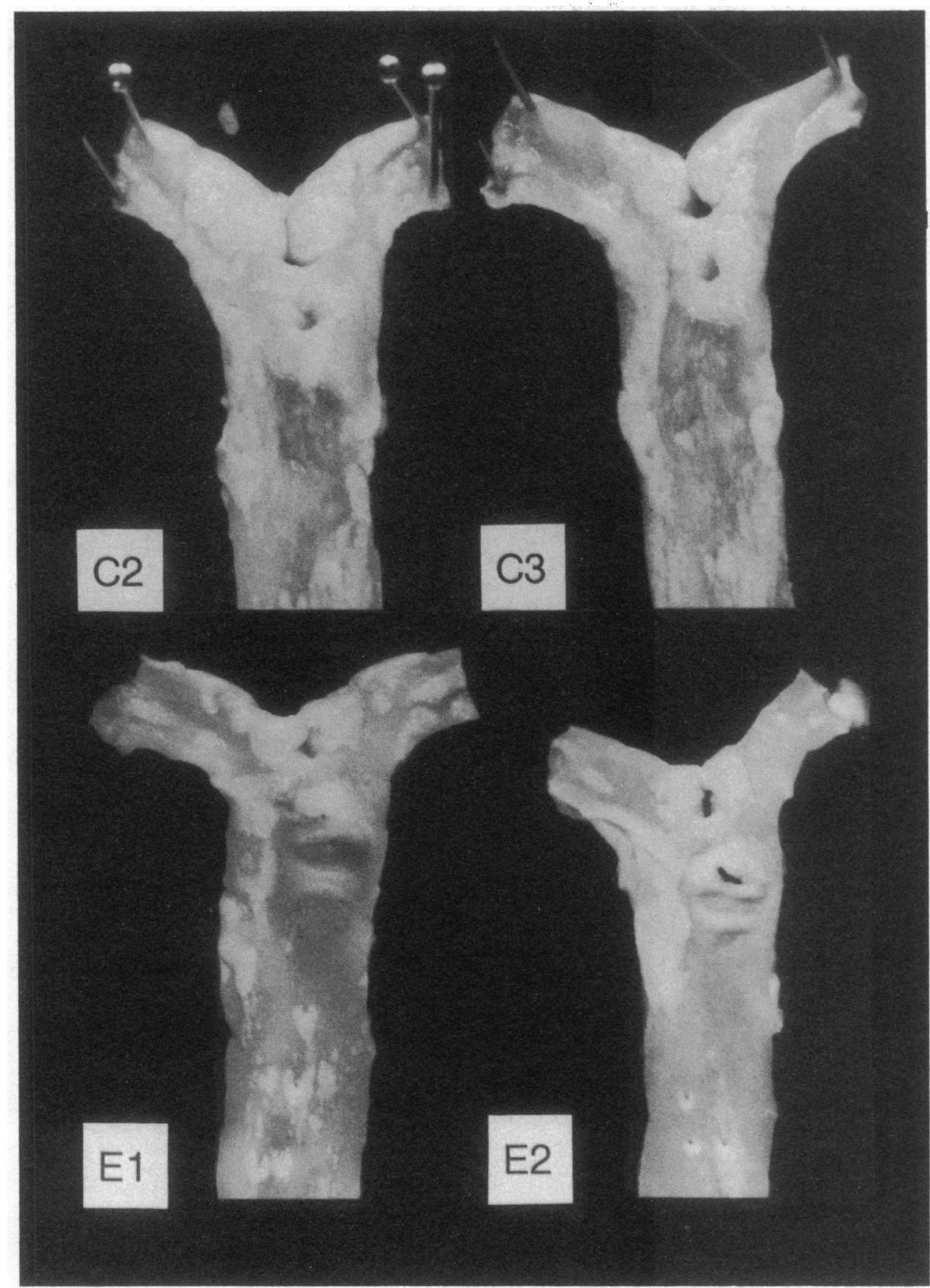

Figure 1. Aortic specimens obtained from WHHL rabbits. The upper two aortae are from rabbits (saline-2 and saline-3) in the saline group. The lower two aortae are from rabbits (apo E-1 and apo E-2) in the apo E group. $10 \mathrm{mg}$ of sterile rabbit apo $E$ in $0.5 \mathrm{ml}$ of $0.15 \mathrm{M} \mathrm{NaCl}$ was administered intravenously by a bolus injection through a marginal ear vein every Monday, Wednesday, and Friday morning for $8.5 \mathrm{mo}$. Animals were killed under deep anesthesia with xylazine at $7 \mathrm{mg} / \mathrm{kg}$ and ketamine at $80 \mathrm{mg} / \mathrm{kg}$ intramuscularly. The entire aorta from the aortic valve to the iliac bifurcation was removed and cleaned of loose adventitial tissue. In the saline group, $0.5 \mathrm{ml}$ of $0.15 \mathrm{M} \mathrm{NaCl}$ was injected as control. onstrated only in WHHL rabbits given probucol (25). Microscopic examination has shown that there was no significant change in subintimal cellular proliferation between the two groups.

Many factors have been suspected of being involved in the generation of foam cells in the arterial wall: accumulation of cholesterol in and efflux of cholesterol from macrophages, recruitment of circulating monocytes, and functions of endothelial cells and smooth muscle cells. If there were an imbalance in these factors such as the high plasma cholesterol level and low HDL cholesterol level found in WHHL rabbits, the rate of atherogenesis would be accelerated. The results of our study suggest that apo $E$ is very effective in correcting the imbalance of factors which determine the rate of atherogenesis. Because there were no significant differences in plasma cholesterol levels between the two groups during the experimental period (Table I), the effects of apo $\mathrm{E}$ on the process of atherosclerosis might not be related to plasma cholesterol level, although there were minimal and acute effects of low dose apo $\mathrm{E}$ on plasma cholesterol levels.

Apo $\mathrm{E}$ secreted from macrophages in peripheral tissues is suggested to be involved in cholesterol transport from peripheral tissues to liver, which is called a reverse cholesterol transport system $(3,15,16)$. Cholesterol-loaded cells such as macro- 


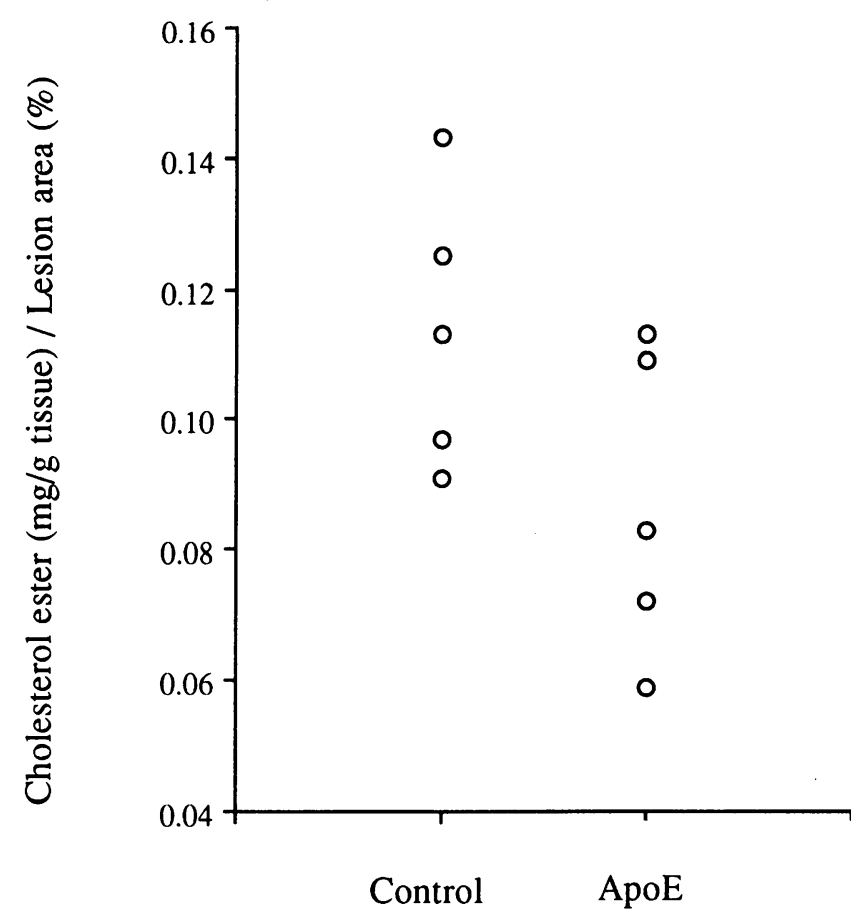

Figure 2. Ratios of cholesterol ester accumulation (mg/g aorta) to percentage lesion area in apo $\mathrm{E}$ and saline groups.

phages release their cholesterol to either HDL or other acceptor proteins including apo $\mathrm{E}$ and apo $\mathrm{Al}$ in the interstitial fluid. In vitro studies showed that the presence of apo $E$ facilitates the acquisition of cholesterol by HDL (15), and apo E itself actively accepts cholesterol from cholesterol-loaded cells (28). HDL with apo E or apo E-lipid complex, after accepting cellular cholesterol, can bind to hepatic receptors including LDL receptors and apo $E$ receptors by virtue of the presence of apo $E$ on lipoproteins. Thus, the extracholesterol accumulating in the subendothelial foam cells can be transported with apo $E$ to the liver, where it is removed by receptor-mediated endocytosis. Because HDL concentrations are low in WHHL rabbits (6-9 $\mathrm{mg} / \mathrm{dl}$ ) as compared to normal rabbits (20-25 mg/dl) (29), exogenous apo E either associated with or without HDL (HDL with apo $E$ or free form of apo E) may help the function of HDL in the reverse cholesterol transport system, and may accelerate the turnover of this system.

In addition to the effects of apo $E$ on lipoprotein metabolism, apo $E$ influences the functions of lymphocytes and smooth muscle cells, which are major cell components of arterial walls. Apo E inhibits mitogenic stimulation of lymphocytes by binding to specific sites on the surface of lymphocytes (30), and apo E produced by smooth muscle cells may be involved in modulating cell proliferation and differentiation (3). It is possible that cellular functions influenced by the presence of apo $\mathrm{E}$ play important roles in reducing the rate of atherogenesis in WHHL rabbits. In addition, macrophage function is important in foam cell formation because an early atherosclerotic lesion is characterized by the presence of macrophage-derived foam cells. Recently, it has been demonstrated that LDL receptor-related protein, a candidate for apo $\mathrm{E}$ receptor, is identical to $\alpha 2$ macroglobulin receptor that appears on macrophages (31). The function of macrophages can be altered by the presence of apo
E through its binding to $\alpha 2$ macroglobulin receptor. The altered function of macrophages may influence the mechanism of foam cell generation in the arterial wall.

In vitro studies demonstrated that lipoproteins rich in apo $\mathrm{E}$ can be actively taken up by macrophages and generate foam cells $(17,18)$. When we studied the uptake of VLDL enriched in apo $E$ which had been incubated with excess apo $E$ in human monocyte-derived macrophages and hep G2 cells, enrichment of apo $\mathrm{E}$ doubled the lipoprotein uptake to a similar extent in both cell types, indicating no preferential uptake of lipoproteins enriched in apo E in macrophages (32). Current results demonstrating no acceleration of the rate of atherogenesis in WHHL rabbits, also suggest that sustained apo $E$ injection does not specifically enhance foam cell formation through the mechanism of the uptake of apo E-rich lipoproteins by macrophages. In the present study, we have investigated an overall effect of apo $E$ in vivo. Although the precise mechanism of apo $\mathrm{E}$ action in the prevention of atherosclerosis is yet unknown, exogenous apo $\mathrm{E}$ may influence the rate of atherogenesis by not only activating the reverse cholesterol transport system but also modifying cellular functions in the arterial wall, rather than by enhancing the cholesterol accumulation in the arterial wall.

\section{Acknowledgments}

We thank Dr. F. Takaku, Dr. T. Murase, and Dr. Y. Akanuma for encouragement and Dr. S. Ishibashi, Dr. H. Mokuno, Dr. K. Takahashi, and Dr. N. Mori for helpful discussions.

This study was supported by Terumo foundation.

\section{References}

1. Brown, M. S., and J. L. Goldstein. 1986. A receptor pathway for cholesterol homeostasis. Science (Wash. DC). 232:34-37.

2. Yamada, N., D. M. Shames, J. B. Stoudmire, and R. J. Havel. 1986. Metabolism of lipoproteins containing apolipoprotein B-100 in blood plasma of rabbits: heterogeneity related to the presence of apolipoprotein E. Proc. Natl. Acad. Sci. USA. 83:3479-3483.

3. Mahley, R. W. 1988. Apolipoprotein E: cholesterol transport protein with expanding role in cell biology. Science (Wash. DC). 240:622-630.

4. Yamada, N., D. M. Shames, and R. J. Havel. 1987. Effect of low density lipoprotein receptor deficiency on the metabolism of apolipoprotein B-100 in blood plasma. J. Clin. Invest. 80:507-515.

5. Yamada, N., M. D. Shames, K. Takahashi, and R. J. Havel. 1988. Metabolism of apolipoprotein B-100 in large very low density lipoproteins of blood plasma. J. Clin. Invest. 82:2106-2113.

6. Hertz, J., U. Hamann, S. Rogne, O. Myklebost, H. Gausepohl, and K. K. Stanley. 1988. Surface location and high affinity for calcium of a $500-\mathrm{kD}$ liver membrane protein closely related to the LDL-receptor suggest a physiological role as lipoprotein receptor. EMBO (Eur. Mol. Biol. Organ.) J. 7:4119-4127.

7. Lund, H., K. Takahashi, R. L. Hamilton, and R. J. Havel. 1989. Lipoprotein binding and endosomal processing of the low density lipoprotein receptor-related protein (LRP) in rat liver. Proc. Natl. Acad. Sci. USA. 86:9318-9322.

8. Yamada, N., H. Shimano, H. Mokuno, S. Ishibashi, T. Gotohda, M. Kawakami, Y. Watanabe, Y. Akanuma, T. Murase, and F. Takaku. 1989. Increased clearance of plasma cholesterol after injection of apolipoprotein $E$ into Watanabe heritable hyperlipidemic rabbits. Proc. Natl. Acad. Sci. USA. 86:665-669.

9. Mahley, R. W., K. H. Weisgraber, M. M. Hussain, B. Greenman, M. Fisher, T. Vogel, and M. Gorecki. 1989. Intravenous infusion of apolipoprotein E accelerates clearance of plasma lipoproteins in rabbits. J. Clin. Invest. 83:2125-2130.

10. Lipid Research Clinics Program. 1984. The lipid research clinics coronary primary prevention trial results. JAMA (J. Am. Med. Assoc.). 251:351-364.

11. Havel, R. J. 1988. Lowering cholesterol. J. Clin. Invest. 81:1653-1660.

12. Basu, S. K., M. S. Brown, Y. K. Ho, R. J. Havel, and J. L. Goldstein. 1981. Mouse macrophages synthesize and secrete a protein resembling apolipoprotein E. Proc. Natl. Acad. Sci. USA. 78:7545-7549.

13. Elshourbagy, N. A., W. S. Liao, R. W. Mahley, and J. M. Taylor. 1985. Apolipoprotein E mRNA is abundant in the brain and adrenals, as well as in the liver, and is present in other tissues of rats and marmosets. Proc. Natl. Acad. Sci. USA. 82:203-207. 
14. Ignatius, M. J., E. M. Shooter, R. E. Pitas, and R. W. Mahley. 1987. Lipoprotein uptake by neuronal growth cones in vitro. Science (Wash. DC). 236:959-962.

15. Gordon, V., T. L. Innerarity, and R. W. Mahley. 1983. Formation of cholesterol- and apolipoprotein E-enriched high density lipoproteins in vitro. $J$. Biol. Chem. 258:6202-6212.

16. Basu, S. K., J. L. Goldstein, and M. S. Brown. 1983. Independent pathways for secretion of cholesterol and apolipoprotein $\mathrm{E}$ by macrophages. Science (Wash. DC). 219:871-873.

17. Bates, S. R., B. A. Coughlin, T. Mazzone, J. Borensztajn, and G. S. Getz. 1987. Apoprotein $\mathrm{E}$ mediates the interaction of $\beta$-VLDL with macrophages. $J$. Lipid Res. 28:787-797.

18. Gianturco, S. H., W. A. Bradley, A. M. Gotto, Jr., J. M. Morisett, and D. L. Peavy. 1982. Hypertriglyceridemic very low density lipoproteins induce triglyceride synthesis and accumulation in mouse peritoneal macrophages. $J$. Clin. Invest. 70:168-178.

19. Ishibashi, S., N. Yamada, H. Shimano, N. Mori, H. Mokuno, T. Gotohda, M. Kawakami, T. Murase, and F. Takaku. 1990. Apolipoprotein E and lipoprotein lipase secreted from human monocyte-derived macrophages modulate VLDL uptake. J. Biol. Chem. 265:3040-3047.

20. Allain, C. C., L. S. Poons, C. S. G. Chan, W. Richmond, and P. C. Fu. 1974. Enzymatic determination of total serum cholesterol. Clin. Chem. 20:470 475 .

21. Bucolo, G., and H. David. 1973. Quantitative determination of serum triglycerides by the use of enzyme. Clin. Chem. 19:476-482.

22. Kano, M., J. Koizumi, A. Jadhav, and G. R. Thompson. 1987. Plasma exchange and low density lipoprotein apheresis in Watanabe heritable hyperlipidemic rabbits. Arteriosclerosis. 7:256-261.

23. Tsukada, T., M. Rosenfeld, R. Ross, and A. M. Gown. 1986. Immunocytochemical analysis of cellular components in atherosclerotic lesions: use of monoclonal antibodies with the Watanabe and fat-fed rabbit. Arteriosclerosis. 6:601613.
24. Kita, T., Y. Nagano, M. Yokode, K. Ishii, N. Kume, A. Ooshima, H. Yoshida, and C. Kawai. 1987. Probucol prevents the progression of atherosclerosis in Watanabe heritable hyperlipidemic rabbit, an animal model for familial hypercholesterolemia. Proc. Natl. Acad. Sci. USA. 84:5928-5931.

25. Carew, T. E., D. C. Schwenke, and D. Steinberg. 1987. Antiatherogenic effect of probucol unrelated to its hypocholesterolemic effect: evidence that antioxidants in vivo can selectively inhibit low density lipoprotein degradation in macrophage-rich fatty streaks and slow the progression of atherosclerosis in the Watanabe heritable hyperlipidemic rabbit. Proc. Natl. Acad. Sci. USA. 84:77257729.

26. Watanabe, Y. 1980. Serial inbreeding of rabbits with hereditary hyperlipidemia (WHHL-rabbit). Atherosclerosis. 36:261-268.

27. Mokuno, H., S. Ishibashi, H. Shimano, T. Gotohda, F. Takaku, and N. Yamada. 1990. Effect of exogenous apo $E$ on the cellular binding of lipoproteins Gerontology. 36:42-48.

28. Hara, H., and S. Yokoyama. 1991. Interaction of free apolipoproteins with macrophages: formation of high density lipoprotein like lipoprotein and reduction of cellular cholesterol. J. Biol. Chem. 266:3080-3086.

29. Havel, R. J., T. Kita, L. Kotite, J. P. Kane, R. L. Hamilton, J. L. Goldstein, and M. S. Brown. 1982. Concentration and composition of lipoproteins in blood plasma of the WHHL rabbit. Arteriosclerosis. 2:467-474.

30. Hui, D. Y., J. A. K. Harmony, T. L. Innerarity, and R. W. Mahley. 1980. Immunoregulatory plasma lipoproteins: role of apolipoprotein $\mathrm{E}$ and apolipoprotein B. J. Biol. Chem. 255:11775-11781.

31. Strickland, D. K., J. D. Adams, S. Williams, W. H. Burgess, M. Migliorini, and W.S. Argraves. 1990. Sequence identity between the $\alpha_{2}$-macroglobin receptor and low density lipoprotein receptor-related protein suggests that this molecule is a multifunctional receptor. J. Biol. Chem. 265:17401-17404.

32. Mokuno, H., N. Yamada, H. Shimano, S. Ishibashi, N. Mori, K. Takahashi, T. Oka, T. H. Yoon, and F. Takaku. 1991. The enhanced cellular uptake of very-low-density lipoprotein enriched in apolipoprotein E. Biochim. Biophys. Acta. 1082:63-70. 